\title{
Cassiano Ricardo
}

\section{e o “mito da \\ democracia racial":}

MARIA JOSÉ

CAMPOS é doutoranda

do Departamento de

Antropologia da FFLCH-

USP.

\section{uma versão}

\section{modernista}

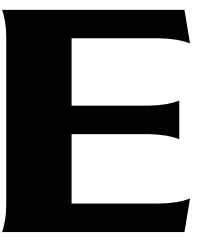

INTRODUட̧Ã̃

tir da leitura de alguns trechos de seus ensaios políticos, escritos entre 1935 e 1940 , recortando, especificamente, a questão da formação racial brasileira'. Analisa-se de maneira mais detida o sentido do discurso em torno do caráter harmonioso das relações raciais no Brasil como uma das linhas de força da reflexão desse autor, articulando de maneira estratégica as suas formulações sobre a particularidade da nacionalidade no Brasil e, principalmente, 50- 
bre a problema da formaçãa e o modo como esse intelectual caracterizou a Estado brasileiro.

A constatação da presença do ideário em torno da democracia racial brasileira no pensamento dos escritores modernistas na década de 1920 incentivou a tentativa de um estuda de caráter histórica que permitisse reconstruir certas trajetórias do conjunto de representaçães que associaram o Brasil a uma deinocracia racial. A avaliação sobre a provável propagação desssa concepção na saciedade da época é realizada a partir do estudo da biografia e da história da carreira do autor?

É importante ressaltar que não se trata aqui de atribuir a uma autoria em específico ou à vertente dos modernistas a origem da idéia da ocorrência de democracia racial no Brasil. Trata-se, sim, de procurar interpretar tal concepção mediante a comprovação da sua difusão entre o máior número possível de autores, a que desembocaria na impossibilidade de provar empiricamente, ou de estabelecer de modo seguro, a proveniência ou um termo inicial para uma representação tão recorrente entre pensadores brasileiros ${ }^{3}$.

A abordagem sobre o tema no pensamento de diversas autores interessa na medida em que propicia, a um só tempo, o descentramento da discussão sobre a democracia racial da obra de Gilberto Freyre e uma maior proximidade com o projeto das elites da época no que se refere à questão das relaçães raciais no Brasil, no âmbito do embate travado.

A formulação mais detalhada desse ideário e a construção de um número maior de perspectivas sobre o tema da democracia racial podem contribuir também para a conhecimento da distância entre a proposta defendida e aquela que efetivamente foi posta em prática. Ainda que um ideário não possa ser confundido de forma direta com a realidade da prática efetiva de um grupo ou 
do poder estatal, seu estudo mais detalhado pode revelar os parâmetros das concepções de uma faixa mais ampla de opiniões políticas dos membros da elite naquele contexto.

Freqüentemente, também, o pressuposto de que há um distanciamento, um afastamento radical, entre ideologia e construção social nos convence a prescindir do conhecimento mais detido sobre o léxico simbólico de um grupo ou de uma época. Dessa maneira, a forma como se articulam os recursos simbólicos dos autores e o modo como são negociados no contexto com os membros das classes interessadas, institucionalizando um modelo formal ou informal de conduta, não são dados a conhecer.

Daí a opção de tomar como versão de referência o pensamento de Cassiano Ricardo. A sua posição ambígua, de escritor e jornalista, no ponto de cruzamento entre a literatura, sobretudo a poesia, e a ação política, torna sua versão em torno da democracia racial brasileira de especial interesse, pois, por se localizar em um terreno movediço de produção, o autor acaba atuando como mediador entre campos cruciais para a compreensão da história cultural brasileira: a literatura e a política. Este trabalho procura avaliar a contribuição desse escritor modernista para a formulação de uma narrativa que acabou se convertendo em um dos pilares da política cultural do Estado Novo: a reinvenção do discurso sobre as raças no Brasil (Gomes, 1996, p. 191).

As leituras de algumas das obras de Cassiano Ricardo são privilegiadas no sentido de ampliar o conhecimento do universo simbólico e da linguagem política existente para que a expressão democracia racial adquirisse sentido no contexto sociopolítico de atuação desse autor. A forma como justifica as instituições políticas existentes, em especial o Estado brasileiro do qual faz parte, torna-se uma porta de entrada para a busca do conhecimento de uma gramática que será a base para as intervenções, inovadoras ou não, dos diversos outros autores e atores posteriores no que se refere à discussão sobre as relações raciais no Brasil.
Nesse sentido, pretende-se enfocar as maneiras como Cassiano Ricardo refletiu sobre os temas "democracia e raça", "democracia étnica" e "democracia racial", com suas variações, atribuindo-lhes significados passíveis de serem investigados e interpretados em contexto. Para isso, o reconhecimento de que a história se constitui como uma máquina de deslocamento de significações em movimento, transportando e soterrando sentidos anteriores (ou seja, aqueles a cujo significado autores ou atores do passado atribuíam determinadas representações que não conhecemos $a$ priori), torna-se fundamental.

Em outras palavras, para compreender o passado, ainda que essa compreensão seja sempre precária, é preciso assumir um distanciamento e uma certa "desconfiança" em relação a noções arraigadas em nosso próprio tempo, muitas vezes até consensuais e amparadas em convenções tácitas. Uma interpretação que pretenda ser minimamente fiel aos textos sobre os quais se debruça e ao contexto estudado não pode pautar-se por significados do presente, ainda que, freqüentemente, sejam eles, em conjunto, o ponto de partida para a investigação.

Obviamente, cada versãoé marcada pela posição de classe de seu autor; ou seja, atende aos seus interesses sociopolíticos. Desse modo, nenhuma versão deve ser analisada de forma ingênua e desinteressada, visto que é elaborada segundo as circunstâncias biográficas e contextuais do narrador, e não há por que não tentar recuperar o seu sentido em uma chave sociológica. É a junção de fragmentos do pensamento dos diversos autores com o cruzamento de suas posições sociais que permitirá uma percepção mais completa sobre as razões da eficácia da narrativa em torno da democracia racial no Brasil. Assumir uma perspectiva que privilegie a busca do significado contextual de uma determinada representação não quer dizer desconsiderar os interesses sociopolíticos que sempre estão em jogo. Trata-se de pesquisar novos fatores para alcançar uma explicação que não se esgotará enquanto a questão permanecer relevante para determinados grupos sociais. 
A tentativa de compreensão de certas relações da expressão democracia racial com outros termos presentes no "universo lingüístico" de Cassiano Ricardo tem como finalidade permitir o levantamento de hipóteses sobre as "razões culturais" da persistência da associação do Brasil a um país onde as raças convivem de forma harmoniosa. Interessa indagar, em última instância, se, para além de todo o ideário nacionalista e patriótico que o autor modernista defendeu e da análise das formas representacionais por ele construídas, é possível inferir em suas concepções fatores culturais e sociais mais abrangentes ${ }^{4}$.

\section{A VERSÃO POLÍTICA DE CASSIANO RICARDO}

Nascido em 1895, na cidade de São José dos Campos, Cassiano Ricardo Leite era filho de Francisco Leite Machado e Minervina Ricardo Leite. O pai, em decadência política e financeira, fez questão que os filhos fizessem cursos superiores. Os dois irmãos, Aristides e Wanda, optaram pela medicina e Cassiano, pelo direito ${ }^{5}$.

Durante a Semana de Arte Moderna, em fevereiro de 1922, Cassiano Ricardo ainda não havia se instalado na capital paulista. Iniciara o curso de direito em São Paulo, porém sua conclusão aconteceu no Rio de Janeiro, na Universidade do Brasil, em $1917^{6}$. Estreara como poeta com o livro Dentro da Noite (1915), mas o livro de poesia que o tornaria realmente conhecido, Martim Cererê, só surgiria em 1928, abordando a temática do encontro das raças em território brasileiro ${ }^{7}$.

Tentaria a carreira de advogado em São José e São Paulo, mas as dificuldades iniciais fizeram com que preferisse instalar-se em uma cidade menor. Em 1918, estimulado por seu cunhado gaúcho, Arthur Caetano, Cassiano se estabeleceu no Sul, com o objetivo de exercer a profissão de advogado, acompanhado pelos pais, pela mulher e o filho, fixando residência na cidade de Vacaria ${ }^{8}$.
Na Região Sul, envolveu-se com o jornalismo e a política partidária, freqüentou residências de coronéis e assumiu certas alianças ao defender, como advogado, pessoas que se contrapunham politicamente ao general Firmino Paim, partidário de Borges de Medeiros, a quem Cassiano faria também oposição ostensiva por meio do jornal $P a ́$ tria, que dirigia ao lado do jornalista André Carrazoni. Nessa época, apoiou e tornou-se amigo de Assis Brasil, o candidato que se opunha à ditadura "borgista", havia vinte e cinco anos no poder. Temendo represália e aconselhado por amigos, seu retorno para a capital paulista deu-se quando se iniciou a revolução no Rio Grande do Sul contra Medeiros.

Por essa época - 1923 - o Movimento Modernista já havia tomado vulto. Já em São Paulo, Cassiano Ricardo estabeleceuse em banca de advocacia e entrou também para a redação do Correio Paulistano, jornal governista do poderoso Partido Republicano Paulista (PRP) - o diário mais antigo da cidade (1854) -, onde Menotti Del Picchia e Plínio Salgado, dois de seus futuros grandes amigos, já trabalhavam ${ }^{9}$. Atuaria como jornalista nesse espaço até 1930, ano em que o jornal seria fechado pelos revolucionários ${ }^{10}$.

Por volta de 1928, Cassiano Ricardo ingressou no serviço público e exerceu o cargo de censor teatral e cinematográfico, abandonando o ofício de advogado. Firmou-se mesmo como funcionário público, em constante contato com políticos importantes, como se verificará no decorrer da década de 1930.

Em 1929, foi requisitado para trabalhar comissionado no Palácio do Governo. Quando veio a Revolução de 30, Cassiano já atuava como auxiliar de gabinete de Júlio Prestes ${ }^{11}$. Após a revolução, no entanto, tendo em vista os contatos que estabelecera no Sul, foi incorporado ao novo governo, sem se considerar desleal à pessoa de Júlio Prestes. “Afinal, exercia eu um cargo efetivo, sem obrigação de me exonerar e deixar de servir a São Paulo por motivo de mudança de governo" (Ricardo, 1972, p. 45). 
Cassiano perderia, sim, por causa da instabilidade política, o cargo efetivo de censor cinematográfico (ao ser nomeado o pintor Di Cavalcanti para o seu lugar), mas não deixaria de atuar como servidor público. Durante as várias trocas de governo, pós-1930, por meio de rearranjos políticos e da criação de cargos burocráticos, assumiria o importante cargo de diretor do expediente do Palácio do Governo do Estado de São Paulo.

Em 1932, presenciou, com satisfação, ser nomeado, para interventor federal no estado de São Paulo, Pedro de Toledo. "Ninguém melhor por seu passado ilustre e serviços ao país. Amigo que ele havia sido de meu pai, ao tempo de Hermes, recordei-lhe o fato, quando ele me designou pra Secretário da Interventoria" (Ricardo, 1972, p. 50). Como ocupante desse cargo, acompanhou todo o desenrolar da Revolução Constitucionalista, viu Pedro de Toledo ser aclamado governador pelos paulistas, assim como a sua queda, no final do episódio ${ }^{12}$. Passado o ápice do conflito, reassumiu, como anteriormente, o cargo efetivo de diretor do expediente ${ }^{13}$.

Na administração de Armando de Salles Oliveira, tanto como interventor federal quanto como governador, a partir de 1935, o modernista de São José dos Campos torna-se amigo pessoal do líder e uma presença fundamental, novamente como chefe de gabinete. Acumulará a direção da revista São Paulo, a primeira em rotogravura no país, patrocinada pelo governo paulista e que circulará pelas mãos da elite política da época ${ }^{14}$.

Um momento de suma importância para a compreensão da história do ideário em torno da democracia racial entre certos intelectuais de São Paulo foi o chamado Movimento Bandeira, apoiado por Armando de Salles, do qual Cassiano Ricardo participou ativamente, já em 1936, ao lado de Menotti Del Picchia e de outros modernistas ${ }^{15}$.

O Movimento Bandeira, além de contrapor-se à vertente integralista de Plínio Salgado, na década de 1930, ao congregar a maior parte dos outros integrantes verdeamarelos com outros intelectuais, como Mário de Andrade e Monteiro Lobato, saiu em defesa de um certo nacionalismo que se opunha a todas as influências estranhas à vida brasileira. Nesse sentido, fazia a crítica não só do fascismo e da democracia liberal como da entrada no país do comunismo, considerado pelo movimento como incompatível com a índole pacífica e os fundamentos cristãos da sociedade brasileira ${ }^{16}$.

Depois disso, durante o governoAdemar de Barros, interventor, desde o começo de 1938, Cassiano Ricardo, já membro da Academia Brasileira de Letras, permanecerá no Gabinete do Governo ${ }^{17}$. Em 1939, ainda no governo Ademar, desloca-se para trabalhar no Rio de Janeiro, na elaboração de outra revista, também em rotogravura, Brasil Novo, do Departamento Nacional de Propaganda, que focalizava, já no panorama nacional, as realizações do Estado Novo, com características similares à revista $S a \tilde{o}$ Paulo $^{18}$. Retorna para a capital paulista após poucos meses, já como diretor do Departamento Estadual de Imprensa e Propaganda do Estado de São Paulo. Em 1941, Cassiano volta para o Rio de Janeiro, por ser escolhido pelo governo de Getúlio Vargas para diretor do jornal A Manhã, importante órgão oficial do Estado Novo, onde atuará de agosto de 1941 a julho de $1945^{19}$.

Apesar de, desde o início dos anos de 1920, manter contato com políticos e personalidades importantes, além de atuar na imprensa, vale assinalar que Cassiano Ricardo só começa a escrever ensaios políticos de fôlego no contexto do Movimento Bandeira. A sistematização em prosa da discussão do autor de São José dos Campos sobre o problema da democracia no Brasil parece ter ocorrido de 1935 a 1940, ano marcado pelo lançamento da obra Marcha para Oeste, na qual procura estender o movimento bandeirante associado a São Paulo para o Brasil como um todo ${ }^{20}$. É no conjunto dos ensaios desse período que o ideário da democracia racial torna-se proeminente no pensamento do autor e culminará em Marcha para Oeste, provavelmente a obra que demonstra o maior investimento de um escritor na fundamentação da existência de uma "democracia tipicamente brasileira", para a qual o argumento da harmonia racial no país é fundamental. 
Marcha para Oeste (1940) foi antecedido pela publicação de $O$ Brasil no Original (1936-37), obra em prosa na qual Cassiano Ricardo pretende abordar a bandeira como fenômeno social e político ${ }^{21}$. Segundo afirmação do próprio autor, no prefácio da segunda edição de $O$ Brasil no Original, o livro "nada mais é do que a interpretação social e política do 'Martim Cererê', aparecido em 1927”' (Ricardo, 1937, p. 5) 22.

Nessa obra, o autor analisa a formação brasileira do ponto de vista geográfico (físico) e histórico, com a intenção de mostrar a contribuição de São Paulo para a construção de uma nacionalidade original no país. Ele exalta o papel da região e dos bandeirantes paulistas nas missões de conquista e de fixação das fronteiras do Brasil, demarcando, assim, a participação decisiva do Estado para a formação nacional no decorrer do processo histórico.

A aliança da raça descobridora com a raça da terra, "sem ódio e sem preconceito de cultura", resultaria em nova forma de vida, com conseqüências inéditas para a humanidade. $\mathrm{O}$ mameluco teria exercido um papel decisivo na bandeira, mas as três raças teriam contribuído para a expansão bandeirante. A preocupação central do autor é garantir a originalidade brasileira instintivamente delineada pela bandeira. Ao praticar a "democracia cristã", a bandeira teria deixado explícita a vocação republicana e democrática do país e delinearia um modelo instintivo de Estado.

Cassiano procura caracterizar a bandeira como um modelo a ser seguido "em sua própria organização” (Ricardo, 1937, p. 34). Os parâmetros de organização da bandeira seriam constituídos por um chefe, que dirigia cada agrupamento, e, pelo menos, um escrivão e um capelão, pois “o bandeirismo foi marcadamente cristão, na luta contra tudo o que era comunismo feroz e monstruoso" (Ricardo, 1937, p. 42). A repartição e a avaliação dos bens seriam feitas também segundo parâmetros cristãos, “o quanto poderiam ser”, "nesse núcleo violentamente instintivo". O autor aponta os jesuítas como os responsáveis pelo fato de o encontro entre raças, ou “da civilização superior com a primitiva" (Ricardo, 1937,p. 62), não se degenerar em desencontro.

No capítulo "Democracia Social”, Cassiano Ricardo procura mostrar que a bandeira conformaria a base da vocação democrática brasileira. Ele afirma que a bandeira era composta pelo encontro das três raças, porém de forma hierarquicamente organizada.

“Mas a verdade não envelhece, como disse alguém. E, embora o elemento predominante das arrancadas tivesse sido o mameluco, cuja primeira geraçãoé a gênese da bandeira, o caso é que esta se utilizou das três raças primitivas para a sua democracia étnica. Isso desde muito cedo, poderia eu acrescentar agora. Estas três cores mesclaram o início de nossa paisagem social e humana com pinceladas justas e admiráveis, mostrando mesmo que, já antes da luta contra o invasor, os três tipos raciais que nos servem de origem se haviam juntado harmônica e harmoniosamente em função de conquista. Com esta circunstância: hierarquicamente dispostos pela função que cada cor adquiriu na organização de cada grupo" (Ricardo, 1937, p. 66).

O autor critica Gilberto Freyre por atribuir ao escravo negro o primeiro gérmen de solidariedade mais larga que a familiar, defendendo que esse gérmen há muito estaria presente na bandeira, em meio às mais diversas formas de associativismo. Enquanto os senhores das casas-grandes representariam a tendência portuguesa da estabilidade patriarcal dos grupos sociais fixos, "a bandeira era a mobilidade social, levando sangue paulista e enlaçando na sua unidade étnica o Brasil todo" (Ricardo, 1937, p. 97).

Cassiano Ricardo associa a bandeira a um Estado moderno em forma de miniatura, com seu pequeno "exército multicor anônimo". "Só um estado, embora pequenino, como o que se locomovia na bandeira poderia resistir a esse vendaval, conservando-se intacto na sua unidade e na sua estrutura social e moral" (Ricardo, 1937,p. 104). Abandeira é que seria o locus
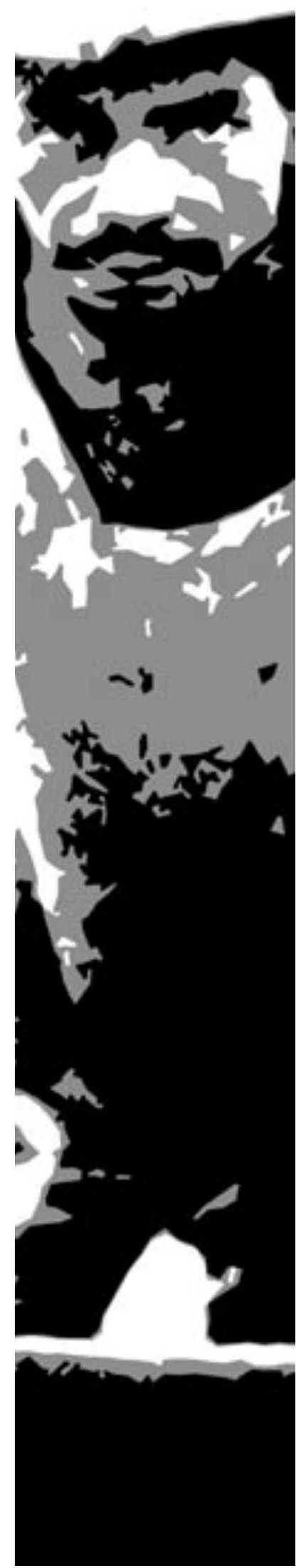


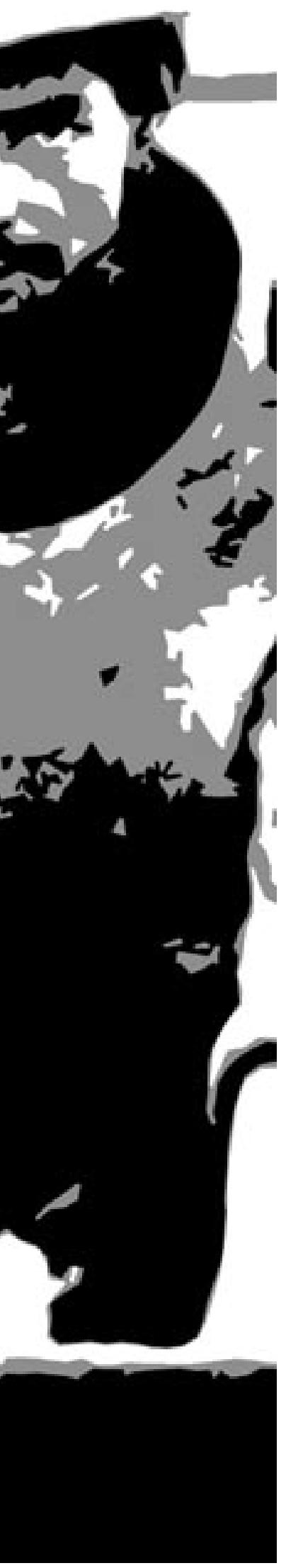

da mestiçagem, ao reunir brancos, pretos e índios, e também da convivência social democrática entre pobres e ricos, "sob a chefia do mais notável".

"A classificação hierárquica dos valores individuais, sociais e étnicos dentro de uma democracia tipicamente brasileira lá está. A condição geográfica e econômica que determina essa democracia foi estabelecida pela bandeira. Esta nos oferece, portanto, os lineamentos de um Estado democrático, social e nacionalista: um Estado moderno, baseado no culto da tradição e doheroísmo" (Ricardo, 1936-37, p. 106).

A empreitada bandeirante caracterizar-se-ia também pela harmonia entre os diferentes, proprietários e não-proprietários de terra.

"De modo que se realizou aquilo a que os entendidos citam sempre como uma das mais importantes funções da bandeira: a de permitir, pela posse da terra, a classificação social desses mestiços superiores, que os preconceitos de raça e de cor subalternizam nos seus meios de origem.

Mesmoos mestiços 'inferiores', que conhecido sociólogo chama de 'infensos à arianização' prestam extraordinário serviço, semo saber, à criação da nacionalidade ${ }^{23}$. Cabras, capangas, curibocas, cafusos, pardos e toda a população anônima que constitui o séquito da bandeira, formam a massa obscura, que não teme o perigo e que não titubeia em avançar, marcialmente, sob a ordem do chefe, contra quaisquer obstáculos, em luta contra o gentio ou contra as forças desabridas do mundo selvagem. [...]

Tudo o que era material humano cabe aí. Todos os inferiores servem. A bandeira os reabilitará e classificará de novo em sua escala hierárquica bioétnica e antropogeográfica, social e moral, psíquica e econômica. Contra o caos selvagem ela é a ofensiva de um pensamento, de uma ação ordenada, de um ímpeto que tem seu rumo a seguir, o seu objetivo a realizar. Em meio dos elementos díspares e inamolgáveis, rebeldes a tudo quanto é poder disciplinador e organizador, ela é a geometria viva que tudo enquadra e retifica. Dentro dela tomam sentido útil as aparas e arestas humanas que a miscigenação jogou fora, que a metrópole abandonou sem lei, que o conflito do meio tropical dispersaram, que a terra deixou de fixar socialmente" (Ricardo, 1937, pp. 67 e 69).

A democracia bioétnica idealizada por Cassiano Ricardo não deixa dúvidas quanto ao caráter hierárquico da reunião das raças na bandeira, marcada pela diferença. Em torno dos chefes estão "enquadrados e disciplinados" os "elementos inferiores", mas "necessários ao organismo de que fazem parte". De uma perspectiva diferente de Oliveira Vianna, Cassiano Ricardo prevê a possibilidade de aproveitamento de todos os elementos para a formação da nacionalidade, mesmo os "inferiores". Nesse sentido, o autor procura alocar os diferentes elementos raciais de uma forma não igualitária, mas que possibilite a cada um ocupar o lugar que lhe cabe. $O$ autor se afirma contrário ao "absurdo biológico das utopias igualitárias” (Ricardo, 1937,p.218), que, além de iludirem o povo, provocariam a desorganização social.

De outro lado, opõe-se ao integralismo e à introdução do fascismo no Brasil, por achar que o racismo característico dessas vertentes "anticristãs e antibrasileiras" ameaçaria a harmonia racial e social do país, semeando a discórdia. "Serábrasileiro, em suma, o nacionalismo integralista? Mas como? Importando o ódio de raça para o único país do mundo onde nunca se falou em semelhante loucura?" (Ricardo, 1937, p. 225).

O que Cassiano procura promover na obra $O$ Brasil no Original, com a sua defesa de uma "democracia hierarquizada", é, ao que parece, a naturalização de uma certa história e a legitimação das diferenças sociais mediante diferenças biológicas, que determinariam a participação de cada raça na formação nacional. A classificação "democrática" de organização da bandeira, contraposta ao racismo na visão do autor, obedeceria a critérios biológicos "naturalmente" hierarquizantes. 
O movimento bandeirante representaria, ainda, um ensaio de "democracia econômica", pelo triunfo individual e pela distribuição de lucros "proporcionalmente" divididos para quem fizesse jus aos mesmos. O autor procura combinar governo forte com classificação social e étnica, o que conformaria, da sua perspectiva, uma democracia realmente brasileira ${ }^{24}$.

“Aidéia de governo forte nasceu da bandeira. Aidéia de disciplina consciente também. A classificação hierárquica dos valores individuais, sociais e étnicos dentro de uma democracia tipicamente brasileira lá está. A condição geográfica e econômica que determinou essa democracia foi estabelecida pela bandeira” (Ricardo, 1936-37, p. 212).

Por meio de uma simbologia bandeirante, Cassiano procura caracterizar todo o país para propagar um modelo de administração política que seguisse o exemplo de São Paulo. Para o autor, o modelo paulista é que seria verdadeiramente democrático e brasileiro. Ele oferecia, assim, uma justificativa possível para a mudança do eixo político e econômico para o centro-sul do Brasil, vivenciada naquele contexto, enquanto afirmava a vocação democrática brasileira associada a uma certa tradição histórica das bandeiras.

Em Marcha para Oeste (Influência da "Bandeira” na Formação Social e Política do Brasil) (1940), em dois volumes, o modernista paulista retoma, desenvolve e esclarece muitos dos argumentos apresentados anteriormente. Exalta, mais uma vez, a confraternização das raças na nossa sociedade. Com base principalmente nessa particularidade, fundamenta o seu projeto de formação do Estado brasileiro.

A pergunta central que motiva a obra é a seguinte: “Qual dos grupos iniciais da formação brasileira é que deu origem à nossa democracia?". O autor argumentará, de forma repetitiva, em favor da associação entre as modalidades de miscigenação e de relações sociais específicas que ele localiza na "Bandeira" e a "vocação democrática" do país.
Cassiano Ricardo associa a formação e a fixação dos grupos humanos ao meio físico e atribui enorme peso à contribuição da geografia, conformada pela bandeira, não só para a unidade brasileira como para a originalidade de sua "democracia biológica", ao misturar o sangue de todas as raças. Do ponto de vista político, a sociedade brasileira caracterizar-se-ia, inicialmente, por três grupos distintos: “[...] o feudal dos engenhos de açúcar, o comunista da região aborígine e o democrático que é o da bandeira colocado entre os dois primeiros" (Ricardo, 1940, p. $4)^{25}$. Todos os grupos seriam etnicamente democráticos, mas a bandeira guardaria as suas especificidades.

Cassiano Ricardo, diante do processo de escravização que atingiu tanto índios quanto negros, apóia-se em Gilberto Freyre e argumenta que tal processo era intrínseco à expansão colonial e à conquista ${ }^{26}$. Para o modernista paulista (Ricardo,1940,p. 91), a escravidão seria resultado da superioridade de um indivíduo sobre outros em um mesmo ambiente cultural ${ }^{27}$.

De outro lado, contrapondo-se a CasaGrande \& Senzala (1933), de Gilberto Freyre, Cassiano afirma que a bandeira representaria a democratização da sociedade colonial, caracterizada pela pequena propriedade e a policultura, em constante mobilidade sociogeográfica, étnica e biológica, e não somente pela "simples miscigenação". Contradita a associação da democracia à idéia de propriedade imobiliária ligada à aristocracia e aos engenhos, regime de grupos fixos da região litorânea.

“A origem democrática do Brasil está na miscigenação, pois. Se assim fosse (estou escutando esta objeção) todos os grupos iniciais da colônia seriam democráticos porque em todos eles se processou a mestiçagem. Mas a diferença começa em que esta mestiçagem se fez mais decisivamente com africanos no norte e no litoral, e com aborígines no sul e no planalto. Ora, na formação dos grupos é preciso atender à complexidade dos grupos étnicos e sociais. O ponto de partida para a democratização pela mestiçagem tem que ser procurado, 
assim, no grupo humano que, não só pela miscigenação e pela localização geográfica como também por outras razões que se reunissem às primeiras, fosse o mais democrático, e o único em tais condições é o de Piratininga.

Explico o que quis dizer. A democratização social que sofria, no litoral e no norte, a restrição tão séria da monocultura, do latifúndio e do escravocratismo, não encontrava o mesmo empecilho no grupo do planalto: muitoao contrário, este se desenvolveu sobre base agrária diferente, que era a policultura; praticando a pequena propriedade em larga escala, nos pequenos sítios que cercavam o arredor de Piratininga; sem o menor apego à propriedade latifundiária, pois o seu objetivo econômico era o das pedras verdes, da prata e do ouro; diminuindo os males do escravocratismo pela mobilidade biológica, econômica e geográfica" (Ricardo, 1940, vol. I, pp. 95 e 96).

Do ponto de vista sociológico, a miscigenação com o branco representaria para o indígena a oportunidade de se classificar melhor. O fundamento da "democracia biológica" seria a inexistência ou o encurtamento das distâncias sociais determinado por essa mestiçagem. Aliás, de antemão, Cassiano Ricardo (1940, p. 15) procurava distinguir entre "comunismo racial" e "democracia biológica”, o primeiro corrigido pela hierarquização das cores presente na modalidade de mistura das raças constitutiva da formação brasileira.

"Encurtamento de distâncias sociais não quer dizer, entretanto, comunismo ou igualitarismo. Não quer dizer supressão das fronteiras individuais ou do próprio indivíduo, ao ponto de ficar esse estandardizado pela concepção igualitária. O espaço entre os indivíduos é tão indispensável como o ar que respiramos.

Claro que a democratização social pela mestiçagem pressupõe miscigenação eugênica e não cacogênica. Pessimistas inveterados preferiam ver, em lugar de uma democracia biológica, a inferiorização do mestiço" (Ricardo, 1940, p. 97).
Na parte final do primeiro volume de Marcha para Oeste, o autor reafirma a participação do negro no bandeirismo. Para ele, os primórdios da colonização já registrariam a entrada dos africanos no Brasil. Tomariam parte no bandeirismo, desempenhando importante papel, principalmente na descoberta dos metais preciosos. Nesse sentido contradita Afonso de Taunay e Alfredo Ellis, para os quais o elemento africano ou seria alheio ao sertanismo ou quase não participaria do bandeirismo ${ }^{28}$. A bandeira começaria mameluca e terminaria africana, segundo Cassiano Ricardo.

"Falar em negro, no período aurífero, era o mesmo que falar em cana-de-açúcar no Nordeste ou, mais tarde, em café no vale do Paraíba. Naépocadobandeirismominerador, negro e ouro andavam juntos. Sem negro não haveria Pernambuco, disse alguém. Estou inclinado a dizer a mesma coisa quanto ao bandeirismo: sem negro não haveria ouro das minas" (Ricardo, 1940, p. 262).

Cassiano não concordava com os autores que diagnosticavam que a situação do negro pudesse ser analisada em termos de inferioridade social.

"Incluir, como pretendeu alguém, a profissão de motorista entre as profissões 'inferiores' que o negro exerce, para provar que ele é inferior sociologicamente (sic) é desconhecer, entre outras coisas, a afirmação de Keysserling, para quem a profissão de chofer é a mais representativa do homem moderno $^{29}$.

Dizer também que o negro é inferior por exercer a profissão de foguista nas estradas de ferroem nada o diminui. Algum escravocrata de mau humor terá dito que 'negro só prafogão'. No entanto, negro foguista ou pra fogão é tão lógico como negro lavrador. Se o negro casa com a terra pelo sedentarismo agrícola a raça negra é a que consegue chegar mais perto do fogo: é a noiva do fogo. Aliás, nada mais absurdo do que estabelecer uma classificação de profissões, que seriam inferiores umas e superiores outras, no país que não reconhece privilégios de classe, e 
numa terra cujos chefes bandeirantes foram, todos, operários. Tais privilégios de profissão seriam verdadeiros disparates numa república cujas melhores condecorações são os calos que cada um de nós traz na mão" (Ricardo, 1940, pp. 273 e 274).

Cassiano Ricardo abre o segundo volume de Marcha para Oeste com o capítulo "O Grupoem Movimentoe aHierarquizaçãodas Cores". Procura, mais uma vez, caracterizar o grupo bandeirante pela divisão do trabalho em função de cada cor, pelo aproveitamento de todos os elementos humanos, mesmo os aparentemente "inúteis ou até prejudiciais", pela classificação dos mestiços, pela posse da terra e pela hierarquização pelo próprio esforço. O critério de utilização dos elementos humanos se faria em virtude das qualidades de cada um, tendo em vista a "psicologia diferencial das raças". Pelo fato de cada cor ter o seu "papel" no grupo, atribui a cada uma um "momento funcional” próprio, todas ligadas por uma "aliança cromática profunda" (Ricardo, 1940, vol. II, p. 5).

Para o autor, democracia quer dizer hierarquia. "Não é possível pensar em democracia sem a organização hierárquica da sociedade, que possibilita a utilização de todos os valores humanos pela capacidade viva de cada um e não pela igualdade abstrata, irracional ou estandardizada". Ele defende que a hierarquização não seria impedimento para a mobilidade social, já que uma raça se fundia com outra, uma classe passava a outra. A bandeira permitia aos índios e negros ocuparem até posições de comando "por delegação do próprio branco" (Ricardo, 1940, vol. II, p. 3) ${ }^{30}$.

A bandeira teria atuado como mediadora contra manifestações extremistas que poderiam levar à fragmentação da unidade nacional. No combate aos “quistos étnicos", a bandeira agiria como um agente integrador, incorporando-os na sua democracia biológica $^{31}$.

"Não obstante, a bandeira foi o terror dos índios e dos quilombolas, todas as vezes que aborígines e negros queriam impedir a democracia étnica brasileira, de que ela era a imagem viva e integral. Isto é, toda vez que o choque se estabelecia entre raças diferentes, a bandeira era a força que reduzia tais quistos étnicos recalcitrantes a uma expressão comum, neutralizando a ação unilateral de um contra o outro. Tal a bandeira contra os bárbaros do Recôncavo Baiano (Matias Cardoso), tal a bandeira contra o Estado Negro (Domingos Jorge Velho). Aqui é que se percebe bem a ação do grupo bandeirante na formação biodemocrática do país" (1940, vol. II, p. 95).

A bandeira seria contra tudo que impedisse o avanço democrático no país. "Numa palavra: contra o feudalismo do litoral, resultante da monocultura escravocrata e latifundiária, e contra o comunismo tribal do hinterland, a democratização do bandeirismo" (Ricardo, 1940, vol. II, p. 113). Para Cassiano, muitos dos episódios vivenciados pelos bandeirantes serviriam como exemplo e modelo para o Estado moderno.

"A lei atual desconhece a distinção de cor, de credo, de origem, mas antes que a lei o fizesse já o grupo bandeirante irmana, classifica, harmoniza e hierarquiza todas as cores na composição social, para o mesmo objetivo econômico e humano. O Estado moderno combate os quistos étnicos e outra coisa não fez a bandeira contra o quisto negro dos palmares e contra o quisto vermelho do Recôncavo. E quando nacionalizarmos as nossas fronteiras atuais, estamos apenas repetindo o gesto dos nossos maiores, que marcaram, no mapa, as fronteiras geográficas dentro das quais se processaria o nosso destino.

Abandeira, portanto, indica os lineamentos de um Estado forte, democrático e nacionalista; um Estado moderno, baseado no culto da tradição e do heroísmo" (Ricardo, 1940, vol. II, p. 127).

Cresce em Marcha para Oeste o número de adjetivos que acompanham o termo democracia, quando o autor acrescenta, além da expressão democracia geográfica a defesa da preservação de uma democracia 
sentimental ou de uma democracia agreste no Brasil.

“Não há mais democracia. O que há são democracias. No plural e cada vez mais em maior número: democracia imperial, democracia coroada, democracia científica, democracia corporativa, democracia bandeirante, democracia igualitária, democracia burguesa e liberal... Não faltará mais alguma? Se a sabedoria contida no 'vox populi, vox Dei' tem razão se ser, e se o povo é a substância viva da democracia, Deus é democrático por excelência. [...] Si se realiza uma democracia liberal ou jurídica, mas não se realiza a econômica, pouco importarão as leis democráticas. Si se realiza a democracia econômica mas não a social, pouco adiantarão as teses sobre economia dirigida. Resultado é que há, sempre crescendo mais, um erro de soma na manipulação jurídica da palavra que terá nascido só para conciliar governo com sentido humano de sociedade. Que adiantariam essas democracias todas, postas de acordo umas com as outras na mesma soma jurídica si não lhes juntasse uma democracia biológica ou racial? Faço a mesma pergunta em termos mais corriqueiros: que adiantaria uma democracia de partidos quando houvesse o ódio de raça dividindo os homens dentro da comunhão?" (Ricardo, 1940, vol. II, pp. 254 e 257).

Assim, no pensamento de Cassiano Ricardo, a formação social brasileira e a democracia aparecem condicionadas a duas determinações centrais de ordem naturalista: a biologia e a geografia. As suas obras apresentam o desenvolvimento de muitos argumentos contrários à introdução da democracia representativa no Brasil. Os argumentos da harmonia histórica entre as raças no Brasil, da "democracia étnica”, da "democracia racial" ou da "democracia social”, vistas como intrínsecas à formação histórica brasileira, são acionados no sentido de dispensar ou revelar como falseamento qualquer defesa dos ideais políticos democráticos e igualitários no país.

\section{DEMOCRACIA E RAC,A}

Um dos objetivos deste artigo foi tentar aprofundar a discussão sobre a concepção de "democracia racial" no Brasil por meio da leitura dos ensaios políticos de Cassiano Ricardo. A associação da "democracia racial” com a ideologia do Estado Novo já foi destacada por Angela de Castro Gomes. Segundo sua visão, o debate em torno da questão racial no Brasil, discussão já clássica desde o século XIX, foi uma das vias diretoras do empreendimento estadonovista, que assumiu a tarefa de formular uma solução-síntese para o problema racial. Para a autora, o empreendimento levado a cabo pelo regime torna o período privilegiado "para perceber como o Estado Novo foi um momento estratégico para a construção do mito da democracia racial brasileira, e mais precisamente ainda, de que maneira tal mito se articulou a uma certa versão da história do Brasil" (Gomes, 1996, p. 192).

Ao analisar a revista Cultura Política, também veículo de propaganda do regime, Gomes assinala, no periódico, a identificação da idéia de "fusão" racial com a de “democracia racial”, como uma operação intelectual cuja pretensão era absorver numa totalidade sem conflitos a diversidade e a desigualdade. "Isso significava, em primeiro lugar, não só que a sociedade brasileira tinha um conteúdo democrático que lhe era 'intrínseco', mas também que esse 'sentimento' nada devia às teorias liberais européias e à idéia de cidadania por elas construída" (Gomes, 1996, p. 194) ${ }^{32}$.

Ao abordar mais de perto a versão de Cassiano Ricardo, procurou-se destacar a hipótese de que as concepções de harmonia e de democracia étnica, racial ou social no pensamento do autor não se restringem a uma operaçãode simples fusão, mas de seleçãodos elementos étnicos mais capazes. Ao tomar como interlocutores não só Oliveira Vianna, como Gilberto Freyre, permanece em seu imaginário a diferenciação hierárquica entre "mestiços inferiores"e "mestiços superiores", resultado de uma seleção de fundo biológico, operada desde o período bandeirante. 
Não por acaso, uma das expressões mais recorrentes no pensamento de Cassiano Ricardo é "democracia biológica", com sentido equivalente a "democracia racial". É essa forma de hierarquização biorracial que vai se constituir como o "padrão étnico" de organização do Estado no imaginário do autor, uma vez que, segundo a sua visão, os lineamentos de um modelo de Estado adequado ao Brasil seriam fornecidos pela bandeira. Além disso, a metáfora organicista, recorrente em seu pensamento, sugere o intuito de alocação dos indivíduos segundo as aptidões e capacidades específicas de cada elemento racial.

Os seus dados biográficos permitem inferir que a concepção da existência de relações raciais harmoniosas repercutiu nacionalmente, de maneira inédita, quando foi assumida como ideologia de formação do Estado brasileiro, legitimada pela importância dos cargos que Cassiano Ricardo alcançou no setor de comunicações e pela sua proximidade com o poder político central, no início dos anos de 1940. Nesse sentido, tal ideologia é inseparável da história do Estado Novo no Brasil, e sua propagação e abrangência não podem ser dissociadas do poder do Estado naquele período.

Como se viu pela leitura de algumas das obras de Cassiano Ricardo, o discurso em torno da democracia racial brasileira, em São Paulo, também não pode ser descolado da questão dos interesses oligárquicos em conflito, das demandas políticas governamentais e da enxurrada de protestos contra a democracia liberal no Brasil, no contexto da crise dos anos de 1920-30. Visando a encontrar uma "solução" para o problema, vários autores argumentaram contra a adoção de um modelo liberal e advogaram a sua inadequação à realidade do país em prol de um Estado forte e autoritário. As diferentes posições defendidas pelos vários autores parecem representar soluções alternativas a um ideário democrático liberal ou igualitário ${ }^{33}$.

Nesse sentido, o contexto de multiplicação de adjetivos que acompanham a palavra democracia, na versão de Cassiano Ricardo, permite, de saída, abrir a análise do ideário da democracia racial, deslocando o eixo do problema para a interpretação dos textos e dos símbolos que esses carregam de uma forma relacional.

Como foi visto, no pensamento de Cassiano Ricardo a expressão democracia racial aparece em oposição a racismo, associado pelo autor aos regimes totalitários e, paralelamente, a comunismo racial, que ele identifica existir também nas tribos indígenas brasileiras e nos quilombos ou "quistos étnicos"34. Diferencia, assim, democracia racial de "igualitarismo racial". O número de adjetivos que acompanham o termo democracia se multiplica em sua versão, mas a expressão mais recorrente em suas obras é democracia biológica, amparada igualmente na noção de raça.

Diante de tal multiplicidade, vale especular um pouco sobre a razão pela qual a expressão democracia racial prevaleceu sobre as demais como símbolo identificador da nação brasileira e ganhou o eixo das discussões posteriores sobre as relações raciais no Brasil. Em outras palavras, surge a pergunta: por que a expressão democracia racial, em certos contextos, possui um valor especial $^{35}$ ?

Uma resposta possível pode ser aventada por meio da análise das categorias que formam a expressão de um ponto de vista conceitual. Apesar de Cassiano Ricardo insistir que democracia significa hierarquia, na tradição rousseauniana da discussão sobre democracia, contra a qual o próprio autor modernista se coloca por considerá-la utópica, o termo assume o valor de igualdade. De outro lado, o termo raça se associa à idéia de diferença, de classificação ou de hierarquia, ao reunir três ou mais etnias díspares (brancos, índios, negros e mestiços) na sociedade brasileira ${ }^{36}$. Ora, a expressão "democracia racial" representa a junção de um par de opostos, aparentemente pertencentes a campos semânticos heterogêneos, formando o eixo que orientou, e ainda orienta, a discussão de diversos autores ao procurarem nomear, ou seja, classificar a experiência e discutir as relações raciais no Brasil, seja por sua afirmação, seja por sua negação, tal e qual as percebem e desejam que sejam percebidas. 
Lévi-Strauss dedica às categorias ambíguas, posicionadas como mediadores entre oposições binárias, uma atenção a mais. $\mathrm{O}$ poder metafórico e o caráter polissêmico de certos símbolos podem ser detectados e residem mesmo nessa ambivalência. Ora, a democracia racial não é senão um desses símbolos transbordantes de valor significativo, por servir como um meio, ou uma tentativa, de transcender a oposição entre democracia e raça. Arelação entre oposições binárias adquire sentidodentro de um sistema significativo socialmente compartilhado, que mobiliza outros pares de opostos, de forma metafórica. Se quiserem, cultura e natureza, idealismo e empirismo, liberdade e autoridade, igualdade e hierarquia, inclusão e exclusão, utopia e realidade, ideologia e mito, num quadro cultural mais abrangente ${ }^{37}$.

Retirada de um contexto específico, a expressão democracia racial pode, de modo paradoxal, designar tanto as simetrias como as hierarquias assentadas na noção de raça, ou de diversidade racial, em um sistema social que se pretenda democrático. Possibilita expressar tanto uma realidade social "naturalizada" de raças hierarquicamente organizadas segundo "seu próprio esforço", como quer Cassiano Ricardo, quanto um quadro de "igualdade racial" utópico ${ }^{38}$. Enfocando a expressão por um prisma menos usual - e é na inversão desse argumento que Cassiano Ricardo tenta driblar a noção de democracia no sentido de igualdade -, enquanto o sistema democrático não encontrar uma maneira de dissolver as desigualdades sociais assentadas na noção de raça, não será também democracia. Será, quando muito, uma “democracia racial”, ou seja, uma democracia condicionada pela variável raça.

Se comparada à expressão democracia biológica, a expressão democracia racial pode ocultarou revelar, dependendodo ponto de vista do leitor, com muito maior eficácia, a idéia de uma "hierarquia eugênica", presente, por exemplo, no pensamento de Cassiano Ricardo, como se tentou demonstrar com o recorte de sua versão. Permite ainda associar ao Brasil, "país da morenidade, da miscigenação e dos contrastes", a imagem ambígua de uma democracia racial, sem necessariamente precisar o significado atribuído a ela. Nesses termos, haja vista a sua polissemia e a importância para esta sociedade do par de opostos que tenta, sem sucesso, conciliar, tornam-se mais compreensíveis a ampla possibilidade de ressignificação da expressão nos mais variados textos e contextos e a persistência da discussão em torno do "mito da democracia racial" em uma história das ciências sociais no Brasil, seja como realidade a ser decifrada ou como ideal a ser perseguido.

\section{NOTAS}

1 Este artigo é resultado das pesquisas parciais referentes à minha tese de doutoramento em desenvolvimento no Programa de Pós-graduação em Antropologia Social da Faculdade de Filosofia, Letras e Ciências Humanas da Universidade de São Paulo.

2 Apesar de este texto estar concentrado nas obras de Cassiano Ricardo, vale assinalar que a abordagem sobre a formação racial brasileira no período, em chaves diversas, é das mais recorrentes. Basta lembrar obras de outros autores modernistas, como Raça, de Guilherme de Almeida, publicada em 1925 e, mesmo, Macunaíma, o Herói sem Nenhum Caráter, de Mário de Andrade, publicado em 1928. No projeto de doutoramento, privilegiei também o enfoque sobre as obras de Menotti Del Picchia, autor aqui não tratado, para permitir uma visão mais detalhada da questão no pensamento de Cassiano Ricardo. Dentre os modernistas, é preciso destacar que a aproximação entre a idéia de fusão racial e a idéia de democracia está já documentada na obra de Graça Aranha, A Estética da Vida, de 1921. "No Brasil o espírito democrático, além de ser o reflexo de toda a evolução social do Ocidente, também foi o resultado da fusão das raças. O sentimento de iqualdade, que se encontra na raiz da democracia, já se vinha afirmando no Brasil desde a época colonial pelo influxo do Cristianismo e pelo prestígio da Revolução Francesa. [...] A Revolucção Francesa veio acentuar ainda mais esse sentimento da igualdade entre os homens. O cruzamento das raças foi afinal o fator decisivo da nossa democracia, em que sem preconceitos, e numa larga tolerância, encontra a sua natural expressão política um povo de origens opostas".

3 Para uma crítica às abordagens que procuram interpretar determinadas formas de representações sociais de uma perspectiva da busca pelas origens, ver não só a crítica estruturalista (Lévi-Strauss, 1985) como o trabalho de Norbert Elias: "Quando - consonância com um hábito ainda muito corrente nos nossos dias - se considera a história como uma sucessão de idéias saída da pena de escritores, das elites, é possível brincar sem desagrado ao jogo de salão que consiste em atribuir um prêmio a qualquer pessoa que consiga encontrar um texto que exprima uma idéia e que seja mais antigo que os textos de que dispõem os outros jogadores. O texto recebe o 'prêmio de prioridade' e o seu autor a taça de 'inventor' da idéia. Quando, pelo contrário, se considera a evolução das formações sociais como a coluna vertebral e o centro nevrálgico do desenrolar da história, compreende-se facilmente que a procura de um princípio absoluto, mesmo o de idéias fixas em livros, é trabalho perdido. Neste continuum de indivíduos interdependentes vivendo em grupos não existe nenhum ponto em que uma determinada estrutura social, uma dada formação, uma certa idéia ou qualquer outro produto individual sejam criados ex-nihilo ou, para ser mais exacto, pelo poder criador de uma pessoa isolada. Em contrapartida, o que é possível observar e verificar são as origens relativas, ou seja, rupturas e descontinuidades explicáveis no tecido do desenvolvimento gradual, na transformação lenta e sempre contínua dos agrupamentos humanos e dos seus produtos" (Elias, 1995, p. 200 - grifos meus). 
4 Para conhecimento da longa discussão nas ciências sociais em torno da expressão e do significado da "democracia racial" no Brasil, ver a retomada da questão por Antonio Sérgio Guimarães no livro Classes, Raças e Democracia (2002), principalmente capítulos 4 e 5. Ver também um texto mais recente, "Intelectuais Negros e Formas de Integração Nacional" (2004), no qual o autor mostra como a ideologia da democracia racial, nos anos de 1940, ganhou rapidamente a adesão dos intelectuais negros, sendo integrada na luta anti-racista. Para uma abordagem antropológica da questão, ver ainda Peter Fry (1996, 2005) e Lilia Schwarcz (1999, 2004).

5 Segundo Cassiano Ricardo (1970), Aristides e Wanda iniciaram o curso de medicina em São Paulo. Aristides finalizou o curso em Belo Horizonte e Wanda só alcançou o segundo ano

6 Na pensão onde residiu no Rio de Janeiro, como estudante de direito, conviveu com vários gaúchos, dentre os quais Cassiano cita Gonçalves Viana, Moisés Antunes Viana, Raul Bopp, Homero Vaz do Amaral e André Carrazoni.

7 A obra de maior repercussão do autor, ou seja, o poema Martim Cererê, narra a história de como as três raças - o índio, o negro e o branco - colaboram para a constituição de um menino brasileiro (Ricardo, 1928, pp. 3-5). Aqui são as cores, os caracteres raciais e o largo processo de mestiçagem que identificam as personagens do poema e procuram construir uma imagem lírica de Brasil. Segundo relato de Ênio Silveira, que fundou e dirigiu a Editora Civilização Brasileira, além de trabalhar na Cia. Editora Nacional, o fato de serem publicadas quatro edições de Martim Cererê, de 1936 a 1947, mostra a receptividade e a consagração do livro. Silveira estimou uma tiragem de 5.000 exemplares para cada edição da obra, número relativamente alto para a época (Moreira, 2001, pp. 71 e 72).

8 "Havia me tornado amigo de Arthur na Universidade, e seu admirador por uma atitude que ele assumiu no Correio Paulistano, a cuio diretor, Carlos de Campos, se apresentara como recomendado de Rui Barbosa" (Ricardo, 1970, p. 9). Arthur Caetano dirigiu inicialmente o movimento revolucionário de 1923 no Rio Grande do Sul, contra a ditadura de Borges de Medeiros. Getúlio Vargas, como deputado do mesmo partido, apoiava Medeiros na época.

9 Apesar de resistir inicialmente às idéias modernistas, Cassiano Ricardo foi protagonista na fundação da revista Novíssima, no final de 1923, que teve um papel fundamental no movimento nos anos seguintes (Guelfi, 1987). A partir de 1924, juntamente com Cândido Motta Filho e Alfredo Ellis Júnior, Cassiano Ricardo, Menotti Del Picchia e Plínio Salgado integrariam o grupo literário Verde-Amarelo, em oposição às idéias de Oswald de Andrade e Mário de Andrade.

10 Cassiano assim descreve sua entrada para o Correio Paulistano: "Como vim a ser redator do Correio Paulistano? Redigindo-the a secção judiciária, e sentando-me no Tribunal de Justiça, ao lado de Noé Azevedo que redigia a do O Estado de São Paulo. Encontro feliz esse" (Ricardo, 1970, p. 35).

11 Como é sabido, o paulista Júlio Prestes venceu Getúlio Vargas nas eleições de 1930, mas o presidente Washington Luís foi deposto por Getúlio.

12 Segundo Cassiano, além de Menotti Del Picchia, trabalhou no Gabinete de Pedro de Toledo, como colaborador, também por ele convidado, Cândido Motta Filho.

13 'É preciso ainda ser dito, um pouco que seja, sobre o 'papel de Martim Cererê na revolução bandeirante de 1932'. É que durante a Revolução Paulista a todo momento ouviam-se no rádio poemas do livro que marcou como um divisor de águas o Movimento Modernista, podendo-se dizer que, a partir dele marcou-se de forma definitiva a chamada ala nacionalista do movimento artístico-literário" (Monteiro, 2003, p. 76).

14 Ricardo Mendes estudou o periódico, lançado em 31 de dezembro de 1935, que procurava retratar o desenvolvimento de São Paulo, durante a administração de Armando de Salles Oliveira, e visava à propaganda políitica. "O que importa é que o periódico constitui um dos primeiros veículos de propaganda políitica com uma roupagem modernizadora" (Mendes, 1994). O depoimento de Cassiano sobre a revista também merece ser registrado: "Posto à venda o primeiro fascículo, numa cifra de 40.000 exemplares (cifra enorme na época), a revista São Paulo esgotou-se em menos de uma semana. Revista espetacular, que era pra divulgação dos empreendimentos bandeirantes, com informações escritas em três línguas, espicaçava a atenção de quem quer que fosse. Remetida para o estrangeiro, causou sensações, talvez superior à revista de mesmo tipo publicada na Rússia. Vicente Rao, ministro de Getúlio, mostrou-a ao Presidente que se havia declarado interessadíssimo em conhecê-la" (Ricardo, 1970, p. 69). Ainda de acordo com Cassiano, Lourival Fontes, que dirigia a propaganda política de Vargas, também se pronunciou: "São Paulo é uma revista que ultrapassa a quaisquer outras publicações do gênero" (Ricardo, 1970, p. 70).

15 Assinam o manifesto do movimento, publicado na imprensa em julho de 1936, além de Menotti Del Picchia e Cassiano Ricardo, Affonso de E. Taunay, Alcântara Machado, Almeida Prado, Fonseca Telles, Guilherme de Almeida, Mário de Andrade, Paulo Prado, Paulo Setúbal, Plínio Barreto, Rubens do Amaral, Reynaldo Porchat, Waldomiro Silveira e Vicente Rao. Cândido Motta Filho também participou do movimento de forma ativa. Como é sabido, Mário de Andrade romperá com o movimento pouco tempo depois.

16 Iniciado oficialmente em julho de 1936, e em diálogo com a produção sobre o bandeirismo paulista já antiga do Instituto Histórico e Geográfico de São Paulo, o movimento rediscutiria a simbologia referente à bandeira, que seria ressignificada por autores como Cassiano Ricardo para conformar um "novo" projeto de nação. "O movimento Bandeira recebe o apoio da alta oficialidade. Personalidades como Góes Monteiro, Gaspar Dutra, Juracy Magallhães parabenizam a iniciativa do grupo, demonstrando a sua solidariedade ao empreendimento. A entidade adquire esfera de ação nacional, tendo órgãos filiados nos mais diferentes Estados: São Paulo, Santa Catarina, Rio de Janeiro, Minas Gerais, Bahia, Pernambuco e Rio Grande do Norte. A estruturação de seus departamentos abrange os seguintes setores: cultura, arte, esporte, operário, serviços sociais, escolar, universitário, propaganda, imprensa, estados, municípios, diversões, feminino, etc. O jornal Anhangüera, fundado em junho de 1937, funciona como porta-voz das idéias do grupo. A sua divisa é 'Por um Brasil nosso e original; por uma democracia social genuinamente brasileira'" (Velloso, 1983, pp. 100 e 101)

17 Cassiano foi eleito para a Academia Brasileira de Letras em 1937 e Menotti Del Picchia em 1943. "O ingresso de Cassiano Ricardo e Menotti Del Picchia [na ABL] durante o Estado Novo (respectivamente 1937 e 1943) se explica em parte pelos serviços que vinham prestando à testa dos aparelhos ideológicos do regime" (Miceli, 2001, p. 256).

18 Para desempenhar a tarefa, Cassiano foi designado por Lourival Fontes. Coube ao jornalista sergipano L. Fontes a direção da propaganda política do governo Vargas de 1934 a 1942. "Vale notar também que a partir de 1939 Lourival Fontes passou a acumular a função de diretor do DIP e a de diretor do Conselho Nacional de Imprensa, cuja tarefa era fiscalizar a imprensa em todo território nacional" (Gomes, 1996, p. 126).

19 A dissertação de Mônica Pimenta Velloso (1983) procura recuperar o papel da ideologia na elaboração do novo modelo político que vigora durante o Estado Novo e centra sua análise no papel que a cultura vai exercer na estratégia político-ideológica do regime de Vargas. Ela focaliza a obra de Cassiano Ricardo como um autor que confere especial ênfase ao papel da cultura, como base da organização política do Estado, mostrando a importância fundamenta desse intelectual na articulação da ideologia que vai legitimar o controle dos aparatos culturais por parte do Estado autoritário. Luiza Moreira (2001) também recupera dados sobre a carreira de Cassiano Ricardo, que mostram o seu trânsito entre os políticos. "Antes do Estado Novo, Cassiano atuara próximo a rivais políticos de Getúlio. Nos anos 20 havia sido redator do Correio Paulistano e ligado ao Partido Republicano Paulista. Nos anos 30 , havia articulado o apoio à candidatura de Armando de Salles Oliveira entre intelectuais, organizando o 'grupo cultural bandeira' em 1936, e chegando a descrever este político como o 'estadista moderno' exemplar em O Brasil no Original. (Como se sabe, Armando de Salles Oliveira era o candidato da oposição a Vargas nas eleições que o Golpe de 1937 impediu)" (Moreira, 2001, p. 28).

20 É preciso assinalar que a campanha contra o liberalismo foi encetada pelos verde-amarelos já a partir de 1927, em artigos para o Correio Paulistano, na qual Cassiano Ricardo tomou parte. Em O Curupira e o Carão, também de 1927, onde estão reunidos artigos da época, Cassiano Ricardo já protestava contra o estabelecimento da democracia representativa no Brasil. "O nosso problema fundamental não está, portanto, na continuação das campanhas cívicas, que Rui encetou. Nem nas curiosas experiências do partido democrático. Não é com o voto secreto e outras medidas teóricas propugnadas pelos continuadores

21 De acordo com a autobiografia de Cassiano Ricardo, a obra O Brasil no Original, de sua autoria (primeira edição de 1935 e a segunda de 1936) despertou a atenção de Getúlio Vargas, resultando daí o convite para a direção do jornal A Manhã (Velloso, 1983, p. 19). No entanto, a data da primeira edição da obra é um pouco controversa. Ás vezes, fala-se em 1935, às vezes, em 1936. A segunda edição é certamente de 1937. 
22 Luiza Franco Moreira (2001) procura recuperar a continuidade no tempo de aspectos da obra intelectual de Cassiano Ricardo que eram tomados anteriormente, às vezes, de forma isolada. Ela demonstra a proximidade de tópicos centrais de Martim Cererê (1928) com Marcha para Oeste (1940) e com os artigos de opinião do autor veiculados no jornal A Manhã, de 1941 a 1945. A imagem transportada do país nos veículos de opinião do Estado Novo por Cassiano, segundo a tese da autora, seria uma retomada da representação de nação composta já na obra poética Martim Cererê e divulgaria uma imagem hierárquica do Brasil. Também de acordo com Mônica Pimenta Velloso (1983), de 1920 a 1940 não se verifica nenhuma transformação substantiva na obra de Cassiano Ricardo, que apresenta um pensamento uniforme ao longo das três décadas.

23 O sociólogo citado por Cassiano Ricardo nesse momento é, obviamente, Oliveira Vianna.

24 Uma dimensão marcante nas obras de Cassiano Ricardo é o generalizado uso de adjetivos que acompanham a palavra democracia em seu vocabulário Por ocasião de sua posse na Academia Brasileira de Letras, em 1937, profere um discurso em que a expressão democracia racial substitui a expressão democracia biológica ou étnica. É em defesa de uma democracia especificamente brasileira e contra a democracia representativa, baseada no sufrágio universal que Cassiano Ricardo direciona sua comunicação na ABL. "Democracia é movimento social e a bandeira foi 'o grupo social mobilíssimo' caminhando por todos os lados em função políitica democratizante. Contra a propriedade imobiliária, que gera a aristocracia, o seu objetivo era a propriedade mobiliária, que democratiza a riqueza individual. Contra a tendência 'vertical' dos núcleos de concentração econômica ela era o 'ímpeto' horizontal que nunca os deixaria crescer apenas verticalmente. Contra os quistos étnicos que impossibilitariam a nossa democracia racial, como o da república negra, ela foi a força descêntrica e niveladora. E enquanto se acentuava o regime feudal dos grupos fixos, nas casas-grandes, a bandeira 'democratizava' a sociedade colonial, misturando-the os elementos e mobilizando-os para a corrida das minas. Nenhum exagero haverá em se dizer que ela não só realizou a sua democracia social e instintiva dentro de cada agrupamento, como também foi a base democrática de nosso grupo nacional" (Ricardo, 1938, pp. 68 e 69 - grifos meus).

25 Cassiano associa primitivismo e comunismo. Para o autor, não haveria grupo mais contrário ao comunismo que a bandeira. "Biologicamente, o comunismo é impedido pela mestiçagem e pela hierarquização das cores nas especializações de funções (mais subjetiva que objetiva) que se processa na bandeira. Economicamente pela distribuição proporcional e classificação social pela posse da terra" (Ricardo, 1940, vol. II, p. 91).

26 Cassiano se diz inspirado em Gilberto Freyre ao escrever Marcha para Oeste. "Confesso mesmo que a idéia de escrever esse modestíssimo ensaio me veio à cabeça por causa de uma afirmação do ilustre autor de 'Casa-Grande \& Senzala' a respeito da nossa democratização social pela mestiçagem" (Ricardo, 1940, vol. I, p. XVIII).

27 Como nota Mônica Velloso, as funções na bandeira seriam distribuídas, segundo Cassiano Ricardo, conforme tendências étnicas ou biopsicológicas, de acordo com as personalidades dos indivíduos e das raças, pois os anseios de liberdade seriam subjetivos e variáveis. "Ora, este homem livre, consciente de sua liberdade e em condições de exercê-la, Cassiano Ricardo o encontra no elemento branco, cuja 'especialidade psicológica' é o comando. Assim, ele é o fundador do Estado, o dominador e o denominador comum capaz de promover a integração nacional. O índio e o negro são os 'heróis anônimos que inconscientemente contribuem para a construção da nacionalidade brasileira, alicerçada na 'biodemocracia'. A sua escravidão pela Bandeira não se constitui, portanto, violentação da sua individualidade e sentimento, na medida em que a Bandeira respeita o seu 'ser cósmico'. Cassiano Ricardo procura mostrar que, na escravidão, a propriedade econômica não se dissocia da sentimental, fato que torna o regime de trabalho forçado perfeitamente compatível com a liberdade individual. O sentimento é que promove a libertação do indivíduo; não importam as condições objetivas que são puramente circunstanciais" (Velloso, 1983, p. 137)

280 capítulo final do primeiro volume de Marcha para Oeste, sobre a participação do negro na bandeira, é a reprodução, com muitas modificações, de um artigo publicado por Cassiano Ricardo na Revista do Arquivo Municipal de São Paulo, em maio de 1938, por ocasião das comemorações do Centenário da Abolição, no contexto do Estado Novo.

29 Cassiano Ricardo faz uma objeção com relação à situação de inferioridade sociológica do negro: "No negro, a aspiração de se classificar melhor não rima suficientemente com a sua mobilidade vertical. O sedentarismo que the é próprio impede ou dificulta essa mobilidade. Mas isso redunda apenas não numa questão de inferioridade mas de hierarquia em que cada um se classifica pelo próprio esforço, pouco importando a cor" (Ricardo, 1940, p. 273).

300 autor afirma que a escravidão foi um mal necessário que favoreceu a miscigenação: "Prova de que a democracia biológica resultou, em grande parte do próprio regimen escravocrata. Prova de que a escravidão foi um mal necessário, mesmo sob o ponto de vista biodemocrático ou apenas biológico. A cruza do índio com preto foi obtida por padres e bandeirantes escravocratas. Queriam estes escravizar o índio mas estavam fazendo, sem o saber justamente o contrário; isto é, corrigindo a separação de cores e suprimindo a distância racial entre índio e preto. Prova de que a mestiçagem é uma reação biodemocrática da raça contra uma condição antidemocrática" (Ricardo, 1940, vol. II, p. 14).

31 Cassiano Ricardo (1940, vol. II, p. 47) aproxima o ideário da democracia dos fenômenos da natureza. Segundo o autor, o topázio, a turmalina e o berilo seriam "jóias democráticas", em contraposição ao diamante, uma preciosidade "aristocrática". O café também é tido pelo autor como "bebida democrática". "No gole de café se igualam, nas fazendas, senhores e escravos. O maior orgulho do pobre é oferecer um gole de café ao patrão ou à visita importante dizendo que i

32 No vasto conjunto de iniciativas governamentais de Getúlio Vargas, a revista Cultura Polífica exerceu um papel fundamental (Gomes, 1988, 1996). Contava com inúmeros colaboradores de prestígio, até mesmo Cassiano Ricardo. Circulou de março de 1941 até outubro de 1945, data da queda do Estado Novo.

33 Não por acaso, em 1936, na obra Raízes do Brasil, Sérgio Buarque de Holanda (1977) tentava esclarecer e demarcar sua posição, ao afirmar: "A democracia no Brasil foi sempre um lamentável mal-entendido".

34 Cassiano Ricardo atribuía a Rousseau as idéias que dariam origem ao liberalismo e ao comunismo. "Num plano cultural, e enquanto Rousseau deformava o índio para a criação de sua teoria, que deu origem ao liberalismo e ao comunismo, a bandeira constituía o melhor desmentido a essa tese, pois fazia ver ao mundo

35 Segundo o etimologista Mário Eduardo Viaro: "Democracia vem do grego demokratía 'poder do povo', composto de dêmos+kratía. O radical de dêmos é vinculado a uma raiz indo-européia *dâ 'dividir, retalhar, rasgar em pedaços', sob uma forma *dâ-mo-s, que especificamente significa 'divisão social', 'parcela da população'. Em sânscrito, baseado na mesma raiz, há o verbo dâti 'cortar, separar' e no próprio grego há o verbo daímai com o sentido de 'corłar em partes', donde outras palavras como: daís 'porção, refeição, oferenda', daitrón 'porção'. Da mesma raiz são ainda a palavra delu no antigo eslavo e Teil no alemão, ambas significando 'parte, parcela'. Essa raiz é muito prolífica, ocupando várias páginas do seguinte dicionário: Pokorny, Julius, Indogermanisches etymologisches Wörterbuch. Bern/München: Francke, 1959, pp. 175-179. Quanto ao termo 'raça' vem do italiano razza, mas de onde vem o termo italiano é bastante obscuro" (correspondência pessoal de 10 de outubro de 2005).

36 Cassiano Ricardo reconhece estar utilizando uma conceituação particular do termo democracia quando trata dos grupos humanos que formaram a sociedade brasileira como grupos distintos aos quais associa a idéia de divisão: "Esta divisão dos grupos humanos que iniciaram a vida social brasileira é indispensável, para se saber qual deles é que deu origem à democracia (democracia no sentido em que tomo esta palavra)" (Ricardo, 1940, p. 4). Algumas vezes porém, o próprio autor associa democracia a justiça e a igualdade. O termo raça, por sua vez, aparece associado tanto a diversidade quanto a unidade. Freqüentemente, o último termo é utilizado por Cassiano no sentido de homogeneidade, quando o autor pensa o Brasil como uma nação miscigenada, em direção à formação de uma "raça futura". De qualquer forma, sua origem seria atribuída no Brasil, segundo o pensamento do autor, à mistura dos três elementos diferentes: branco, índio e negro.

37 Para uma abordagem sobre o posicionamento relacional dos símbolos e as "coisas fora de lugar", ou seia, que violam as categorias conceituais, ver Robert Darnton (1995). "Coisas que deslizam entre as categorias, que se encavalam nas divisões ou se espalham para fora das margens, ameaçam nosso senso básico de ordem. Solapam-nos o terreno epistemológico. Essas coisas são potentes e perigosas. E também possuem um nome, pelo menos na antropologia: são tabu" (Darnton, 1995, p. 290). 
38 Redefinir a expressão democracia racial, caracterizando-a como mito ou ideologia, com o objetivo de desmascarar ou reverenciar a sua especificidade, por meio de juízos valorativos, pode ter como contrapartida o aumento da capacidade multiplicativa desse ideário em novas versões, que não cessam de reaparecer em seu incessante movimento espiralar, uma vez que a expressão é, por definição, imprecisa. De outro lado, desaconselhar o seu uso ou sugerir a sua proibição, transformando-a em tabu, não é senão acentuar o seu caráter significativo.

\section{BIBLIOGRAFIA}

ARANHA, Graça. A Estética da Vida. Rio de Janeiro, Livraria Garnier, 1921.

DARNTON, Robert. "História e Antropologia", in O Beijo de Lamourette. São Paulo, Companhia das Letras, 1995.

ELIAS, Norbert. A Sociedade de Corte. Lisboa, Editorial Estampa, 1995.

FRY, Peter. "Feijoada e Soul Food: Notas sobre a Manipulação de Símbolos Étnicos e Nacionais", in Ensaios de Opinião, v. 4. Rio de Janeiro, 1977.

. "Por que o Brasil é Diferente?", in Revista Brasileira de Ciências Sociais, no 31. São Paulo, Anpocs, 1996. . A Persistência da Raça. Rio de Janeiro, Civilização Brasileira, 2005.

GOMES, Angela de Castro. A Invenção do Trabalhismo. Rio de Janeiro, Vértice, 1988. . História e Historiadores. Rio de Janeiro, Fundação Getúlio Vargas, 1996.

GUELFI, Maria Lúcia Fernandes. Novíssima Contribuição para o Estudo do Modernismo. São Paulo, IEB-USP, 1987.

GUIMARÃES, Antonio Sérgio. Classes, Raças e Democracia. São Paulo, Editora 34, 2002. . "Intelectuais Negros e Formas de Integração Nacional", in Estudos Avançados, 18 (50). Dossiê 0

Negro no Brasil. São Paulo, IEA-USP, 2004.

HOLANDA, Sérgio Buarque de. Raízes do Brasil. Rio de Janeiro, José Olympio, 1977.

LÉVI-STRAUSS, Claude. "A Estrutura dos Mitos", in Antropologia Estrutural. Rio de Janeiro, Tempo Brasileiro, 1985. . O Pensamento Selvagem. Campinas, Papirus, 1989.

MENDES, Ricardo. "A Revista S. Paulo: a Cidade nas Bancas", in Imagens (3). Campinas, Unicamp, dez./1994.

MICELI, Sergio. Imagens Negociadas. São Paulo, Companhia das Letras, 1996. . Intelectuais à Brasileira. São Paulo, Companhia das Letras, 2001. . Nacional Estrangeiro. São Paulo, Companhia das Letras, 2003.

MONTEIRO, Amilton Maciel. Cassiano. Fragmentos para uma Biografia. São José dos Campos, Univap, 2003.

MORAES, Eduardo Jardim de. A Brasilidade Modernista: sua Dimensão Filosófica. Rio de Janeiro, Graal, 1978.

MOREIRA, Luiza Franco. Meninos, Poetas e Heróis - Aspectos de Cassiano Ricardo do Modernismo ao Estado Novo.

São Paulo, Edusp, 2001.

PICCHIA, Menotti Del. Juca Mulato. São Paulo, Casa Editora “0 Livro”, 1921. . Por Amor do Brasil (Discursos Parlamentares). São Paulo, Editorial Helios, 1927.

RICARDO, Cassiano. Borrões de Verde Amarelo. São Paulo, Editorial Helios, 1925. . Martim Cererê ou o Brasil dos Meninos, dos Poetas e dos Heróis. São Paulo, Editorial Helios, 1928. . Deixa Estar, Jacaré... São Paulo, Empresa Gráfica da Revista dos Tribunais, 1931. . O Brasil no Original. São Paulo, Bandeira, 1937.

. "O Negro no Bandeirismo Paulista", in Revista do Arquivo Municipal. Ano IV, vol. XLVII. São Paulo,

Departamento de Cultura, maio de 1938. Recepção de Cassiano Ricardo na Academia Brasileira. São Paulo, Bandeira, 1938. . Marcha para Oeste: a Influência da "Bandeira" na Formação Social e Política do Brasil. Rio de Janeiro,

José Olímpio, 1940. . Viagem no Tempo e no Espaço (Memórias). Rio de Janeiro, José Olympio, 1970.

RICARD0, Cassiano; SALGADO, Plinio \& PICCHIA, Menotti Del. 0 Curupira e o Carão. São Paulo, Editorial Helios, 1927. SCHWARCZ, Lilia Moritz. 0 Espetáculo das Raças, Companhia das Letras, São Paulo, 1993.

. "Questão Racial e Etnicidade", in S. Miceli (org.). 0 Que Ler na Ciência Social Brasileira (1970-1995)

Antropologia, vol. I. São Paulo, Sumaré/Anpocs/Capes, 1999.

São Paulo, 2004. Memorial. Concurso de titularidade. São Paulo, Departamento de Antropologia/FFLCH, Universidade de

VELLOSO, Mônica Pimenta. O Mito da Originalidade Brasileira: a Trajetória Intelectual de Cassiano Ricardo (dos Anos

20 ao Estado Novo). Dissertação de mestrado. Rio de Janeiro, PUC, 1983.

. "A Brasilidade Verde-Amarela: Nacionalismo e Regionalismo Paulista", in Estudos Históricos, vol. 6, nº

11. Rio de Janeiro, 1989.

VIARO, Mário Eduardo. Por Trás das Palavras. Manual de Etimologia do Português. São Paulo, Globo, 2003. 